\title{
Association between Quality of Sleep and its Effect on Glycaemic Control in Patients with Type 2 Diabetes Mellitus- A Pilot Study
}

\author{
By Dr. Firas Rauf Mammoo \& Prof. Dr. S. Girija
} Introduction- Diabetes mellitus is a common metabolic disease. Nowadays, sleep complaints are increasing day by day due to the restriction in bed time resulting in chronic partial sleep loss. ${ }^{(1)}$ Type 2 diabetes mellitus accounts for $95 \%$ of all of diagnosed diabetes worldwide. Several studies have recognized sleep disorder as a novel risk factor for diabetes. ${ }^{(2)}$ Sleep disorder plays a vital role in the development of diabetes via various metabolic and neuroendocrine pathways. ${ }^{(3)}$ Nocturia and neuropathic pain were explained as two possible causes of decreased sleep quality. (1) People who have sleep disorder either in the quality or quantity experienced reduced insulin sensitivity, which results in elevated blood glucose that can aggravate the progress of diabetes. There are limited studies from India on the association of sleep quality and diabetes control status. In this study, we aimed to find the quality of sleep in patients with type 2 diabetes mellitus and its correlation with glycaemic control.

GJMR-B Classification: NLMC Code: WK 810

Strictly as per the compliance and regulations of:

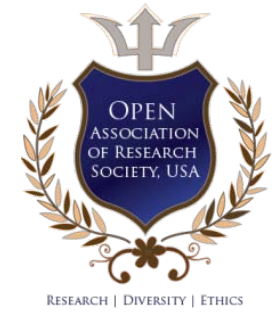

(C) 2020. Dr. Firas Rauf Mammoo \& Prof. Dr. S. Girija. This is a research/review paper, distributed under the terms of the Creative Commons Attribution-Noncommercial 3.0 Unported License http://creativecommons.org/licenses/by-nc/3.0/), permitting all noncommercial use, distribution, and reproduction in any medium, provided the original work is properly cited. 


\title{
Association between Quality of Sleep and its Effect on Glycaemic Control in Patients with Type 2 Diabetes Mellitus- A Pilot Study
}

\author{
Dr. Firas Rauf Mammoo ${ }^{\alpha}$ \& Prof. Dr. S. Girija ${ }^{\sigma}$
}

\section{INTRODUCTION}

$\int$ Not iabetes mellitus is a common metabolic disease. Nowadays, sleep complaints are increasing day by day due to the restriction in bed time resulting in chronic partial sleep loss. ${ }^{(1)}$ Type 2 diabetes mellitus accounts for $95 \%$ of all of diagnosed diabetes worldwide. Several studies have recognized sleep disorder as a novel risk factor for diabetes. ${ }^{(2)}$ Sleep disorder plays a vital role in the development of diabetes via various metabolic and neuroendocrine pathways. ${ }^{(3)}$ Nocturia and neuropathic pain were explained as two possible causes of decreased sleep quality.(1) People who have sleep disorder either in the quality or quantity experienced reduced insulin sensitivity, which results in elevated blood glucose that can aggravate the progress of diabetes. There are limited studies from India on the association of sleep quality and diabetes control status. In this study, we aimed to find the quality of sleep in patients with type 2 diabetes mellitus and its correlation with glycaemic control.

\section{il. Material and Methods}

It is a hospital record-based descriptive and cross-sectional analytical study involving patients with type 2 diabetes mellitus. The patients for the study were recruited from the outpatients and inpatients attending the Department of General Medicine of Sri Manakula Medical College and Hospital for a period six months after obtaining ethical committee approval.

Sample size: The sample size was determined by a single population- proportion formula with the assumptions of the 95\% confidence level, $7.5 \%$ precision. The sample size was calculated for variables such as poor sleep quality, which is $33.8 \%$, and considering a $10 \%$ non-responses rate; the sample size was further increased to 160 respondents. ${ }^{(1)}$

Patients over 18 years old with a duration of diabetes more than one year were recruited for the study.

Patients with type 1 diabetes, gestational diabetes, or other specific types of diabetes, patients

Author $\alpha$ : Post graduate in department of general medicine, SMVMCH, Puducherry.e-mail: firasrauf@gmail.com

Author $\sigma$ : Professor in department of general medicine, SMVMCH, Puducherry.e-mail: girijagops@gmail.com with acute diabetic complications, severe heart diseases, lung diseases, and cerebral diseases, patients with mental illness, and those with intelligence or cognitive impairment was excluded from the study.

Data collection procedure: Necessary data were collected in two stages. The details like demographic, risk factors, diabetic control, biochemical indicators $\mathrm{HbA1c}$, complication, etc. were extracted in the questionnaire from the OPD and IP registration card. The patients fulfilling the inclusion criteria were recruited for the study after obtaining informed consent. Quality of sleep was measured using pittsburgh quality of sleep index, which measures seven components, which included subjective sleep quality, sleep latency, sleep duration, habitual sleep efficiency, sleep disturbances, use of sleep medications, and daytime dysfunction over the last one month.

Data analysis: As a first step, the frequency tables were obtained for discrete variables such as sociodemographic characteristics, risk factors, diabetic status, biochemical indicators, $\mathrm{HbA1c}$, waist-hip ratio, and body mass index, and complications. Continuous variables were expressed as mean and standard deviation. Chisquare (x2) test was applied to proportions to find the level of significance which is fixed at $p<0.05$. Confidence interval $(\mathrm{Cl})$ set at 95\%. Ethical principles such as respect for the persons, beneficence, justice, and ensuring confidentiality and privacy adhered to throughout the study. Ethical clearances was obtained from the institutional ethical committee.

\section{ili. Results}

A total of 160 patients with type 2 diabetes mellitus were recruited for the study. The sociodemographic and clinical characteristics of the patients are shown in Table.1. The mean (SD) age of the patients was $55.5(12.1 \%)$ years. One-fourth of patients had Diabetes Mellitus for more than five years. Almost three-fourth (117 patients) had uncontrolled PPBS, and three- fifths (94 patients) had uncontrolled FBS; in total, $79.4 \%(n=127)$ had an uncontrolled type 2 diabetes mellitus status. The proportion of patients with $\mathrm{HbA} 1 \mathrm{c}>$ 6.1 was $91.9 \%$. Quality of sleep was deficient in $18.1 \%$ (95\% Cl 12.5-24.9) (Figure.1). Around two-fifths $(n=61$, $38 \%$ reported hypertension as co-morbidity. 
The correlation between PSQI with the duration of type 2 diabetes mellitus, FBS, PPBS and $\mathrm{HbA} 1 \mathrm{c}$ are depicted in Table 2. There was a moderately positive correlation between PSQI score and PPBS $(r=0.53)$ and low positive correlation for FBS $(r=0.33)$ and $\mathrm{HbA} 1 \mathrm{c}$ $(r=0.49)$.

The association of age, gender, duration of diabetes, fasting, postprandial blood glucose, and $\mathrm{Hba1c}$ on sleep quality are shown in Table 3 and Table 4. Compared to a younger age group, diabetic patients aged 51-60 years had a higher risk of poor glycaemic control $(\mathrm{aPR}=1.34)$. Males had uncontrolled diabetes compared to females but were not found to be statistically significant $(a P R=1.01, p=0.91)$. Having hypertension with type 2 diabetes mellitus had 1.16 times higher risk for poor glycaemic control. Type 2 diabetes mellitus duration for more than five years increases the chance of uncontrolled DM ( $\mathrm{aPR}=1.21$, $p=0.02$ ).

\section{Discussion}

Short term studies have shown that disturbed or reduced sleep is associated with glucose intolerance and insulin resistance, thus predisposing the individual to type 2 diabetes mellitus. One potential mechanism includes reciprocal changes in circulating levels of leptin and ghrelin, which in turn increases appetite and obesity. ${ }^{(6)}$ Sleep deprivation is said to decrease insulin production by increasing cortisol levels. Patients with diabetes tend to have many intrinsic and extrinsic sleep disorders.

This study was done to assess the quality of sleep and its relation with glycaemic control among type 2 diabetes mellitus patients using PSQI and the results showed that $18 \%$ of our study patients were having poor sleep (PSQI > 5), which is less than what other studies showed. (1) The mean (SD) of total PSQI score was 3.75 (2.7\%), and this was similar to a study done in the USA by Luyster and Dunbar-Jacob. ${ }^{(7)}$ But it was lower than other studies which reported a higher mean score of PSQI. ${ }^{(3-5)}$ A meta-analysis conducted in 2010 reported poor sleep quality as a known risk factor for T2DM. ${ }^{(6)} \mathrm{A}$ study showed that a reduction of sleep by 2 hours for one week in young, healthy men and women were associated with a significant increase in the secretion of pro-inflammatory cytokines IL6 and TNF $\alpha$ which can lead to increased insulin resistance and cardiovascular disease. ${ }^{(8)}$

The current study showed a moderate positive correlation between PSQI score and HbA1c. Patients with high $\mathrm{HbA1c}$ levels tend to have increased symptoms such as thirst, nocturia, and neuropathic pain, which could lead to short sleep duration and poor sleep quality. ${ }^{(7)}$ Similarly, poor sleep quality leads to elevation of the levels of cortisol, IL-6, and TNF $\alpha$, resulting in activation of the sympathetic nervous system that promotes insulin resistance. ${ }^{(8,9)}$ Reduction in sleep duration may interfere the daytime activities and may prevent the patient from adherence to medications, diet and exercises. There is a need for more studies to understand the mechanisms underlying.

The present study indicated that $79 \%$ of the patient's glycaemic status were not under control (FBS $>125 \mathrm{mg} / \mathrm{dl}$ or PPBS $>200 \mathrm{mg} / \mathrm{dl}$ ). These findings are similar to a large pan-India cross- sectional registry study conducted by Borgharkar et al. between 2015 and 2017. ${ }^{(10)}$ Our results showed that only age, duration of diabetes, and poor sleep quality are the independent predictors of uncontrolled T2DM. These findings were in agreement with the results of some studies. ${ }^{(1,}{ }^{11)}$ Younger patients with diabetes mellitus ( $<50$ years) were found to be associated with poor glycaemic control due to high insulin resistance. ${ }^{(14)}$

Our study found that duration of diabetes is one of the determinants of poor glycaemic control. A study conducted by Herrington et al. also identified the effect of long duration on poor glycemic control. ${ }^{(12)}$ Deficient sleep quality is associated with a higher number of comorbidities, higher number of diabetic complications and depression as reported by Luyster in his study. ${ }^{(7)}$

The limitations of this study could be that the majority of the study population were men (62\%), and gender variations of sleep and diabetes are not adequately addressed. Only selective patients were questioned which may give results that might not be representative of the entire population with diabetes. Finally, no information on psychological parameters, type of medications, medication adherence, and comorbidities other than hypertension that might affect diabetes control was collected. No objective validation of sleep by means of polysomnography, EEG or EMG were done.

\section{Conclusion}

It is imperative to assess sleep in all patients with diabetes mellitus, and if needed a complete sleep study may be recommended. If identified, strategies to improve sleep quality and psychological consultation should be provided.

\section{References Références Referencias}

1. Knutson KL, Ryden AM, Mander BA, Van Cauter E. Role of sleep duration and quality in the risk and severity of type 2 diabetes mellitus. Archives of internal.

2. Wu Y, Ding $Y$, Tanaka $Y$, Zhang W. Risk factors contributing to type 2 diabetes and recent advances in the treatment and prevention. International journal of medical sciences. 2014; 11(11): 1185.

3. Briançon-Marjollet $A$, Weiszenstein $M$, Henri $M$, Thomas A, Godin-Ribuot D, Polak J. The impact of sleep disorders on glucose metabolism: endocrine 
and molecular mechanisms. Diabetology \& metabolic syndrome. 2015 Dec; 7(1): 25.

4. Iliescu EA, Coo H, McMurray MH, Meers CL, Quinn MM, Singer MA, et al. Quality of sleep and healthrelated quality of life in haemodialysis patients. Nephrology, dialysis, transplantation: official publication of the European Dialysis and Transplant Association - European Renal Association. 2003 Jan; 18(1): 126-32.

5. Ghanei R, Hemati-Maslak-Pak M, Ghosi S, HosseinPour H, Amin-Pour E, Baghi V. Restless legs syndrome and the quality of sleep in type II diabetes. FEYZ. 2011 Sep 1; 15(3): 240-6.

6. Cappuccio FP, D'Elia L, Strazzullo P, Miller MA. Quantity and quality of sleep and incidence of type 2 diabetes: a systematic review and meta-analysis. Diabetes care. 2010 Feb; 33(2): 414-20.

7. Luyster FS, Dunbar-Jacob J. Sleep quality and quality of life in adults with type 2 diabetes. The Diabetes Educator. 2011 May; 37(3): 347-55.

8. Vgontzas AN, Zoumakis E, Bixler EO, Lin H-M, Follett $H$, Kales A, et al. Adverse effects of modest sleep restriction on sleepiness, performance, and inflammatory cytokines. The Journal of clinical endocrinology and metabolism. 2004 May; 89(5): 2119-26.

9. Spiegel K, Leproult R, Van Cauter E. Impact of sleep debt on metabolic and endocrine function. Lancet (London, England). 1999 Oct; 354(9188): 1435-9.

10. Borgharkar SS, Das SS. Real-world evidence of glycemic control among patients with type 2 diabetes mellitus in India: the TIGHT study. BMJ Open Diabetes Research \& Care. 2019 Jul 1; 7(1): e000654.

11. Cunha MCB da, Zanetti ML, Hass VJ. Sleep quality in type 2 diabetics. Revista latino- americana de enfermagem. 2008; 16(5): 850-5.

12. Herrington WG, Alegre-Díaz J, Wade R, Gnatiuc L, Ramirez-Reyes R, Hill M, et al.

13. Effect of diabetes duration and glycaemic control on 14-year cause-specific mortality in Mexican adults: a blood-based prospective cohort study. The Lancet Diabetes \& Endocrinology. 2018 Jun 1; 6(6): 455-63.

14. Nilsson PM, Roost M, Engstrom G, Hedblad B, Berglund $G$. Incidence of diabetes in middle-aged men is related to sleep disturbances. Diabetes care. 2004 Oct; 27(10): 2464-9.

Table 1: Sociodemographic and clinical details $(\mathrm{N}=160)$

\begin{tabular}{lcc}
\hline Variable & $\mathrm{n}$ & $\%$ \\
\hline Age in years & 55 & 34.4 \\
Up to 50 & 48 & 30.0 \\
$51-60$ & 57 & 35.6 \\
60 above & & \\
Gender & 100 & 62.5 \\
Male & 60 & 37.5 \\
Female & & \\
Hypertension & 61 & 38.1 \\
Yes & 99 & 61.9 \\
No & & \\
Diabetes duration & 119 & 74.4 \\
Upto 5 years & 41 & 25.6 \\
More than 5 years & & \\
FBS control status & 66 & 41.3 \\
Controlled & 94 & 58.8 \\
Uncontrolled & & \\
PPBS control status & 43 & 26.9 \\
Controlled & 117 & 73.1 \\
Uncontrolled &
\end{tabular}

Table 2: Correlation between PSQI with DM duration, FBS, PPBS, HBA1C ( $N=160)$

\begin{tabular}{cc}
\hline Variable & Correlation coefficient \\
\hline DM duration & 0.141 \\
FBS & 0.327 \\
PPBS & 0.533 \\
Hba1c & 0.493 \\
\hline
\end{tabular}


Table 3: Association of sleep, Sociodemographic and clinical factors with FBS and PPBS $(N=160)$

\begin{tabular}{|c|c|c|c|c|c|}
\hline \multirow[b]{2}{*}{ Variable } & \multicolumn{2}{|l|}{ T2DM } & \multirow[b]{2}{*}{ Crude PR } & \multirow[b]{2}{*}{ Adjusted PR } & \multirow{2}{*}{$\begin{array}{l}P \\
\text { value }\end{array}$} \\
\hline & $\begin{array}{c}\text { Uncontrolled } \\
\text { (FBS }>126 / \text { PPBS }>183)\end{array}$ & $\begin{array}{c}\text { Controlled } \\
\text { (FBS } \leq 126 / \text { PPBS } \leq 183)\end{array}$ & & & \\
\hline \multicolumn{6}{|l|}{ Age in year } \\
\hline Up to 50 Years & $48(87.3)$ & $7(12.7)$ & 1.26 & 1.34 & 0.01 \\
\hline $51-60$ & $33(68.8)$ & 15 (31.3) & 1 & 1 & - \\
\hline 60 above & $46(80.7)$ & $11(19.3)$ & 1.17 & 1.14 & 0.252 \\
\hline \multicolumn{6}{|l|}{ Gender } \\
\hline Female & 47 (78.3) & $13(21.7)$ & 1 & 1 & - \\
\hline \multicolumn{6}{|l|}{ DM duration } \\
\hline Up to 5 years & $90(75.6)$ & $29(24.4)$ & 1 & 1 & 0.02 \\
\hline $\begin{array}{l}\text { More than } 5 \\
\text { years }\end{array}$ & 37 (90.2) & $4(9.7)$ & 1.19 & 1.21 & - \\
\hline \multicolumn{6}{|l|}{ Hypertension } \\
\hline Yes & 53 (86.9) & $8(13.1)$ & 1.16 & 1.08 & 0.321 \\
\hline No & $74(74.7)$ & $25(25.3)$ & 1 & 1 & - \\
\hline \multicolumn{6}{|l|}{ Sleep Quality } \\
\hline Poor & 27 (93.1) & $2(6.9)$ & 1.22 & 1.17 & 0.022 \\
\hline Good & $100(76.3)$ & 31 (23.7) & 1 & 1 & - \\
\hline
\end{tabular}

Table 4: Association of sleep, sociodemographic and clinical factors with $\mathrm{HbA1c}(\mathrm{N}=160)$

\begin{tabular}{|c|c|c|c|c|c|}
\hline \multirow[b]{2}{*}{ Variable } & \multicolumn{2}{|c|}{ T2DM } & \multirow[b]{2}{*}{ Crude PR } & \multirow[b]{2}{*}{ Adjusted PR } & \multirow[b]{2}{*}{$P$ value } \\
\hline & $\begin{array}{l}\text { Uncontrolled } \\
(\text { Hba1c }>6.1)\end{array}$ & $\begin{array}{c}\text { Controlled } \\
(\mathrm{Hba1c} \leq 6.1)\end{array}$ & & & \\
\hline \multicolumn{6}{|l|}{ Age in year } \\
\hline Up to 50 Years & $53(96.4)$ & $2(3.6)$ & 1.08 & 1.14 & 0.039 \\
\hline $51-60$ & $43(89.6)$ & $5(10.4)$ & 1.01 & 1.02 & 0.290 \\
\hline 60 above & $51(89.5)$ & $6(10.5)$ & 1 & 1 & - \\
\hline \multicolumn{6}{|l|}{ Gender } \\
\hline Male & $93(93.0)$ & $7(7.0)$ & 1.03 & 1.02 & 0.697 \\
\hline Female & $54(90.0)$ & $6(10.0)$ & 1 & 1 & - \\
\hline \multicolumn{6}{|l|}{ DM duration } \\
\hline Up to 5 years & $106(89.1)$ & $13(10.9)$ & 1 & 1 & 0.001 \\
\hline \multicolumn{6}{|l|}{ Hypertension } \\
\hline Yes & $59(96.7)$ & $2(3.3)$ & 1.09 & 1.05 & 0.200 \\
\hline No & 88 (88.9) & $11(11.1)$ & 1 & 1 & - \\
\hline \multicolumn{6}{|l|}{ Sleep Quality } \\
\hline Poor & $29(100)$ & $0(0)$ & 1 & 1.08 & 0.014 \\
\hline Good & $118(90.1)$ & $13(9.9)$ & 1 & 1 & - \\
\hline
\end{tabular}




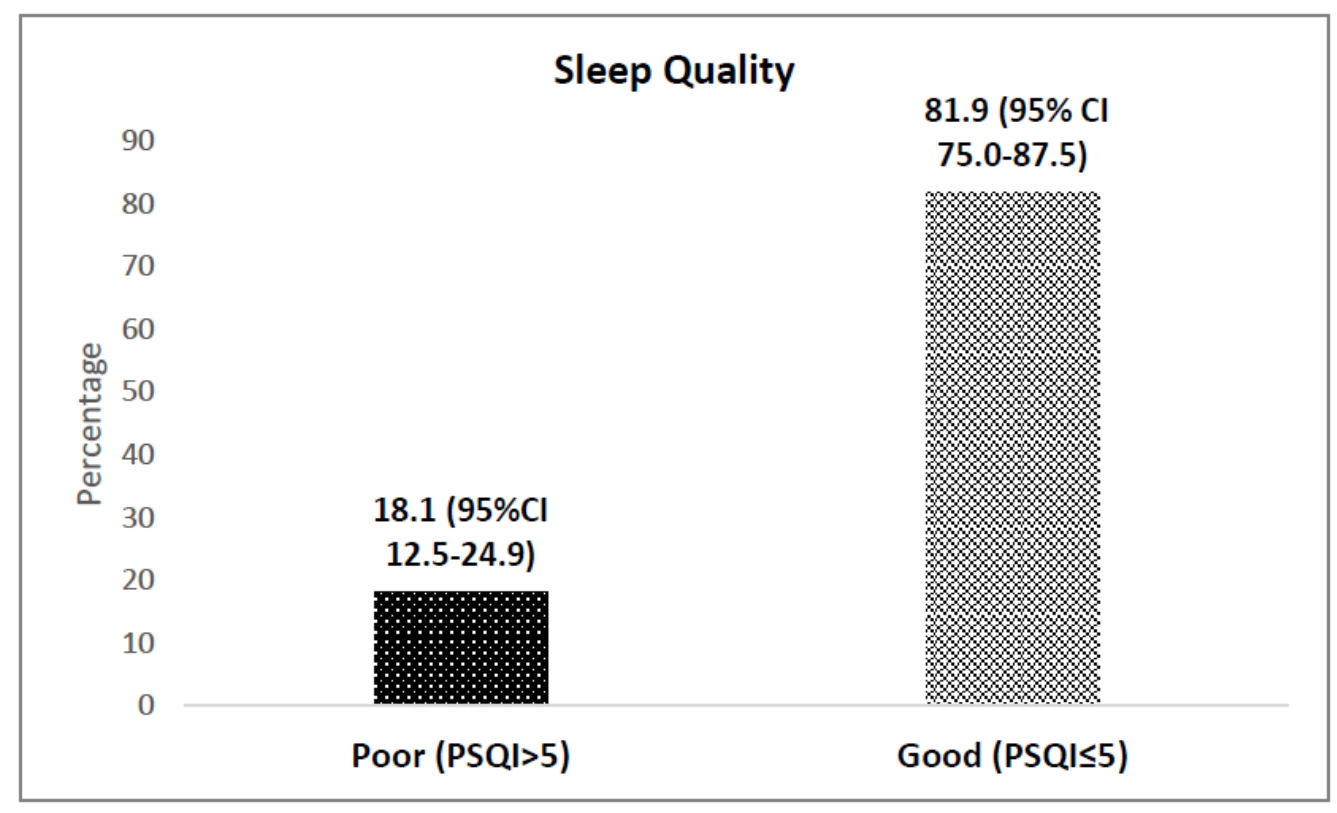

Figure 1: Prevalence of poor sleep among Type 2 Diabetes Mellitus patients 